\title{
AC 2007-146: DO TINKERING AND TECHNICAL ACTIVITIES CONNECT ENGINEERING EDUCATION STANDARDS WITH THE ENGINEERING PROFESSION IN TODAY'S WORLD?
}

\section{Dale Baker, Arizona State University}

Dale R. Baker is a Professor of Science Education in the Department of Curriculum and Instruction at Arizona State University and was the Co-Editor of The Journal of Research in Science Teaching. She teaches courses in science curricula, teaching and learning, and assessment courses with an emphasis on constructivist theory and issues of equity. Her research focuses on issues of gender, science, and science teaching. She has won two awards for her research in these areas. She was elected a fellow of the American Association for the Advancement of Science in 2004.

\section{Stephen Krause, Arizona State University}

Stephen J. Krause is Professor and Associate Director of the School of Materials at Arizona State University. He teaches courses in general materials engineering, polymer science, characterization of materials, and materials selection and design. He conducts research in innovative education in engineering, including a Materials Concept Inventory, and also in adapting design, engineering and technology concepts to K-12 education. 


\title{
How Well Do Tinkering and Technical Activities Connect Engineering Education Standards with the Engineering Profession in Today's World?
}

\begin{abstract}
The ABET Criterion 3 a-k learning outcomes have been used for more than a decade and have had a major influence on the structuring and evaluation of engineering curricula. As such, they should have a significant impact on the perceptions of what engineers believe are the important factors in the education of engineering students. This research explores the question of whether the technical and tinkering characteristics that engineers value correspond with ABET Criterion 3 a-k learning outcomes. To answer this question a volunteer sample of engineering students and ASEE engineering faculty and practicing engineers responded to two open-ended prompts. These were, "List the characteristics of someone with good tinkering skills" and, "List the characteristics of someone with good technical skills". The method used to gather and analyze data was grounded in the descriptive study survey approach. A list of 300 statements was generated from this sample which were grouped by overarching themes (e.g. "good with hands" or "manual dexterity" under the theme of "Hands") and functioned as definitions for the themes.
\end{abstract}

The statements were examined to determine if there were significant differences across the three groups of respondents. No differences were found and the data was aggregated and a word search, derived from the themes, was conducted for the definitional statements. From this the top 15 themes were ranked each for technical and tinkering characteristics, based on word frequency. Some themes appeared for both technical and tinkering but had different rankings, which resulted in a total of 24 themes. These rankings indicate that, on the whole, technical or tinkering skills represent different domains of characteristics of engineers. Next, the statements associated with the top themes were compared to the Criterion 3 a-k outcomes. Nine of the 24 themes contained definitional statements that did not correspond with the Criterion 3 a-k outcomes and an additional three had some, but not all, statements that corresponded with the Criterion 3 outcomes. Thus, approximately half of the themes of what engineers valued related to tinkering and technical characteristics corresponded to Criterion 3 outcomes. There was not much correspondence, however, to the soft outcomes such as Criterion 3 (f), an understanding of professional and ethical responsibility and Criterion 3 (d), an ability to function on multidisciplinary teams. The lack of correspondence indicates that the soft outcomes do not appear to be explicitly incorporated with tinkering and technical activities, thinking processes, or decision making processes of students, faculty and practicing engineers. Additionally, themes representing curiosity and creativity, which were of the utmost importance to engineers, with a ranking as first and second as tinkering characteristics, do not appear in the Criterion 3 a-k outcomes. Furthermore, engineers value habits of mind, such as persistence, that are also incorporated into the Criterion 3 outcomes. The differences between the characteristics that engineers associate with tinkering and technical activities and the Criterion 3 learning outcomes suggest that the ABET criteria may need to be reviewed, discussed, or debated in light of changes in the profession in the innovation-driven global economy. 


\section{Introduction}

The ABET Criterion $3 \mathrm{a}-\mathrm{k}$ learning outcomes have been used for a decade and have had a major influence on the structuring and evaluation of engineering curricula. Consequently, we should expect that the perceptions of what engineers believe are also important characteristics for engineers to acquire during their education or may be intrinsic characteristics of their personality. Thus, it would be expected that the skills engineers bring to the practice of engineering have a strong degree of correspondence to these characteristics. This research was based on this expectation and has multiple purposes. First, it examines to what extent the tinkering and technical characteristics valued by engineers correspond with the ABET Criterion 3 a-k learning outcomes. Second, it explores to what extent tinkering and technical characteristics and Criterion 3 outcomes support women's participation in engineering and what the implications for design of engineering curricula. Third, it serves as a starting point for the development of a technical and tinkering self-efficacy instrument that will reflect both the perceptions of the engineering community as well as the ABET learning outcomes.

Tinkering and technical characteristics of engineers were chosen for study because there is a rich literature that indicates that a person's perception of their efficacy in these areas has an influence on their persistence and their success in engineering education. This is especially true for women. Thus, it is important to know what engineers in business, industry and academia, as well as engineering students, deem important and value. That is because it is likely that these characteristics will be emphasized in the preparation of future engineers at universities and will have a significant impact on female engineering students.

When developing an instrument to measure self-efficacy, it is also important to understand the perspectives of practitioners. Bandura ${ }^{1}$ states that the first step in creating items for a selfefficacy instrument is to draw on expert knowledge about what a person must be able to do in order to be successful in a given pursuit. This can be done through a variety of means such as open-ended surveys, interviews or questionnaires. The work being presented here utilized an open-ended survey and discussions with engineers.

\section{Tinkering and Technical Self-efficacy}

Tinkering self-efficacy refers to one's experience, competence, and comfort with manual activities. Specifically, it is the confidence and belief in one's competence to engage in activities such as manipulating, assembling, disassembling, constructing, modifying, breaking and repairing components and devices, (e.g. assembling a bicycle or taking apart a computer). Women's lack of experience in using tools and machinery and taking things apart and putting them together contributes to low tinkering self-efficacy. Thus, tinkering experience favors males. In one study, Crismond ${ }^{2}$ found that even academically well-prepared female students at a technical high school were fearful of simple mechanical devices (e.g. nutcrackers) and tentative in handling them when engaged in engineering design activities. In contrast, male students were confident and explored the devices to the fullest. In another study, Margolis and Fisher ${ }^{3}$ found that female computer science majors at a university did not, when playing with computers, take them apart and then reassemble them. In contrast to their male counterparts, tinkering was not 
something women chose to do in their free time while growing up and, as a consequence, they felt unprepared.

Technical self-efficacy refers to confidence and belief in one's competence to learn, regulate, master and apply technical academic subject matter. Baumert, Evans, and Geiser ${ }^{4}$ found that gender influenced technical self-efficacy, which in turn affected technical problem-solving. The women in their study had lower self-estimates of competence and technical problem solving scores than the men and attributed their failure to lack of ability rather than to lack of persistence. This is in sharp contrast to women's perceptions of their problem-solving abilities and persistence in mathematics, a foundational skill for success in engineering. In the case of mathematics, women believed they were better and more persistent problem-solvers than males ${ }^{5}$. However, even women in engineering majors who intended to go on to graduate school or who were already in graduate school expressed less efficacy in their technical abilities than did their male counterparts ${ }^{6,7}$. Even male engineering students who drop out of engineering have greater technical self-efficacy than the females who graduate as engineers ${ }^{8}$.

\section{Methodology}

The method used to gather and analyze data was grounded in the descriptive study survey approach. The question posed was what technical and tinkering characteristics engineers deemed important and to what extent these characteristics corresponded to the ABET Criterion 3 a-k learning outcomes. To answer this question a volunteer sample of engineering faculty, students, and practicing engineers, who are members of ASEE, were recruited. They were asked to respond to two open-ended prompts on a survey in paper and pencil format and electronically.

These prompts were; 1) List the characteristics of someone with good tinkering skills, and 2) List the characteristics of someone with good technical skills. No definitions of technical or tinkering skills were given to avoid biasing the respondents' answers. Responses ranged from one word, to phrases, to answers that were several sentences long.

The sample consisted of 71 members of ASEE, 24 engineering students in a design course at a large university located in the southwest, and 6 engineering faculty at the same institution. There was a total of 101 respondents. Data on the ethnicity of participants was not collected and the number of females in the sample was very small. Consequently, the data was not examined by ethnicity and gender.

The respondents wrote 598 statements that described the tinkering characteristics of engineers and 237 statements that described the technical characteristics of engineers with some characteristics listed by multiple respondents. For example, creative was listed by 20 different respondents. Using a common qualitative approach, the statements were grouped by overarching themes to facilitate data analysis. As a check against bias and subjectivity, a second researcher who was unfamiliar with the purpose of the research also examined the data for themes as well as the statements grouped under the themes and suggested modifications. These modifications were discussed until agreement was reached between the first author and second researcher. The themes are listed in Table 1. Note that, despite having fewer statements generated for technical 
characteristics, there was a broader range of characteristics listed and therefore a longer list of themes.

Table 1. Technical and Tinkering Skills Themes

\begin{tabular}{|l|l|}
\hline Technical Skills Themes & Tinkering Skills Themes \\
\hline Knowledge/background & Knowledge/background \\
\hline Technical & Technical \\
\hline Problem(s) & Problem(s) \\
\hline (How things) work & (How things) work \\
\hline Think/reason & Think/reason \\
\hline Tool(s) & Tool(s) \\
\hline Creative & Creative \\
\hline Analytical & Analytical \\
\hline Interest & Interest \\
\hline Hands-on & Hands-on \\
\hline Curious/inquisitive & Curious/inquisitive \\
\hline Theory & (take) apart \\
\hline Persisten(t/ce) & Persisten(t/ce) \\
\hline Experience & Experience \\
\hline Mechanical & Mechanical \\
\hline Detail & Detail \\
\hline Tinker & Tinker \\
\hline Educate(d) & Educate(d) \\
\hline Visual/spatial & Visual/spatial \\
\hline Smart/intelligent & Smart/intelligent \\
\hline Intuitive & Intuitive \\
\hline Computer & Patient \\
\hline System(s) & System(s) \\
\hline Dexterity & Dexterity \\
\hline Risk/failure & Risk/failure \\
\hline Science & Science \\
\hline (Willingness to)learn & (Willingness to)learn \\
\hline Imagination & Imagination \\
\hline Break (things) & Break (things) \\
\hline Precise & Detail \\
\hline Solution & Solution \\
\hline Invent & Invent \\
\hline Practical & Practical \\
\hline math & math \\
\hline Open-minded & Open-minded \\
\hline Model & \\
\hline Fundamentals/principles & \\
\hline Solution & \\
\hline Research & \\
\hline & \\
\hline
\end{tabular}




\begin{tabular}{|l|l|}
\hline Methodical & \\
\hline Patient & \\
\hline Abstract & \\
\hline Concepts & \\
\hline Read & \\
\hline (take) apart & \\
\hline Communicate & \\
\hline Design & \\
\hline Logic & \\
\hline
\end{tabular}

The statements were next examined to determine if there were major differences across the three groups of respondents using percentages. Chi square could not be used to evaluate the data because of the frequency of empty cells and cells with less than five occurrences, which violated the assumptions of the procedure. After it was determined that no differences existed, the data was aggregated and a word search, using the themes, was conducted on the statements. The word search allowed the themes to be ranked from most frequent to least frequent.

The second author, who had extensive experience with ABET reviews, and the first author then examined the themes for the degree of correspondence with the ABET Criterion 3 a-k outcomes. As with the determination of themes, decisions about correspondence were carried out separately by each researcher. Differences in the decisions of the two researchers were discussed until $100 \%$ agreement was reached.

\section{Results and Discussion}

The word search resulted in generating a ranking of the top 15 themes each for technical and tinkering characteristics of engineers based on word frequency. Some themes appeared for both technical and tinkering but had different rankings (see Table 2). These rankings indicate that, on the whole, technical and tinkering skills represent different domains of characteristics of engineers.

Table 2. Rankings of Technical and Tinkering Characteristics Themes

\begin{tabular}{|l|l|l|l|}
\hline Technical Skills Themes & Ranking & Tinkering Skills Themes & Ranking \\
\hline Knowledge/background & 1 & Curious/inquisitive & 1 \\
\hline Math & 2 & Creative & 2 \\
\hline Problem(s) & 3 & (How things) work & $3($ tie) \\
\hline Concepts & 4 & Think/reason & $3($ tie) \\
\hline Think/reason & 5 & Tool(s) & 5 \\
\hline Creative & $6($ tie) & Problem(s) & 6 \\
\hline Analytical & $6($ tie) & Imagination & $7($ tie) \\
\hline Communicate & $6($ tie) & Knowledge/background & $7($ tie) \\
\hline Technical & $9($ tie) & Hands-on & $7($ tie) \\
\hline Theory & $9($ tie) & (take) apart & 10 \\
\hline (How things) work & $11($ tie) & Persisten(t/ce) & 11 \\
\hline Tool(s) & $11($ tie) & Technical & 12 \\
\hline
\end{tabular}




\begin{tabular}{|l|l|l|l|}
\hline Design & $11(\mathrm{tie})$ & Mechanical & $13(\mathrm{tie})$ \\
\hline Logic & $11(\mathrm{tie})$ & Tinker & $13(\mathrm{tie})$ \\
\hline Experience & $11(\mathrm{tie})$ & Visual/spatial & 15 \\
\hline Smart/intelligent & $16(\mathrm{tie})$ & (Willingness to)learn & $16(\mathrm{tie})$ \\
\hline Read & $16(\mathrm{tie})$ & Intuitive & $16(\mathrm{tie})$ \\
\hline Computer & $16(\mathrm{tie})$ & Patient & $16(\mathrm{tie})$ \\
\hline System(s) & $19(\mathrm{tie})$ & Experience & $16(\mathrm{tie})$ \\
\hline Detail & $19(\mathrm{tie})$ & Dexterity & $16(\mathrm{tie})$ \\
\hline Analytic & $19(\mathrm{tie})$ & Risk/failure & $21(\mathrm{tie})$ \\
\hline Science & $19(\mathrm{tie})$ & Smart/intelligent & $21(\mathrm{tie})$ \\
\hline (Willingness to)learn & $23(\mathrm{tie})$ & Open-minded & $21(\mathrm{tie})$ \\
\hline Patient & $23(\mathrm{tie})$ & Interest & $21(\mathrm{tie})$ \\
\hline Fundamentals/principles & $23(\mathrm{tie})$ & System(s) & $21(\mathrm{tie})$ \\
\hline Model & $26(\mathrm{tie})$ & Analytical & 26 \\
\hline Curious/inquisitive & $26(\mathrm{tie})$ & Break (things) & $27(\mathrm{tie})$ \\
\hline Precise & $28(\mathrm{tie})$ & Detail & $27(\mathrm{tie})$ \\
\hline Methodical & $28(\mathrm{tie})$ & Solution & $29(\mathrm{tie})$ \\
\hline Interest & $30(\mathrm{tie})$ & Educate(d) & $31(\mathrm{tie})$ \\
\hline Educate(d) & $30(\mathrm{tie})$ & Invent & $31(\mathrm{tie})$ \\
\hline Practical & $30(\mathrm{tie})$ & Practical & $31(\mathrm{tie})$ \\
\hline Practical & $30(\mathrm{tie})$ & Science/math & $31(\mathrm{tie})$ \\
\hline Visual/spatial & $30(\mathrm{tie})$ & & \\
\hline Hands-on & $30(\mathrm{tie})$ & & \\
\hline Mechanical & $36(\mathrm{tie})$ & & \\
\hline Invent & $36(\mathrm{tie})$ & & \\
\hline Solution & $36(\mathrm{tie})$ & & \\
\hline Research & $36(\mathrm{tie})$ & & \\
\hline Risk/failure & $40(\mathrm{tie})$ & & \\
\hline Persisten(t/ce) & $40(\mathrm{tie})$ & & \\
\hline Abstract & $40(\mathrm{tie})$ & & \\
\hline Solution & $40(\mathrm{tie})$ & & \\
\hline & & & \\
\hline
\end{tabular}

The top 15 themes for both characteristics (Technical: Knowledge/Background to Experience, Tinkering: Curious/Inquisitive to Visual/Spatial) were compared to the ABET criterion 3 a-k outcomes. This decision was based on the word count. Themes with a word count of less than 15 were not examined. This cut off was chosen to address the issue of sample size needed for conducting a factor analysis that will be part of the development of the tinkering and technical self-efficacy instrument. This cut off resulted in a total of 24 themes. This number is less than 30 because of duplication of themes on the two sets of skills. Note however that, despite duplication, the ranks of the duplicated themes are different.

\section{Non-corresponding Themes}

Nine of the 24 themes contained statements that did not correspond with Criterion 3 a-k outcomes. These themes were Experience, Curious/Inquisitive, Imagination, Hands-on, Take 
Apart, Persisten(t/ce), Mechanical, Tinkerer, and Visual/Spatial. The Curious/Inquisitive and Imagination themes contained affective statements and were ranked first and seventh indicating that the respondents perceive these skills to be quite important skills. However they do not appear explicitly in the ABET Criterion 3 learning outcomes. One reason may be that the needs of the engineering profession have changed as the world has shifted toward an innovation-driven global economy. If so, it may be that characteristics that foster innovation, such as intrinsic curiosity about the world and an active imagination, should be examined with respect to the ABET criteria. These characteristics incline a person towards engineering and contribute to successful invention, design and development of innovative products. Although the characteristics of curiosity and imagination may be intrinsic qualities of a person, like eye color, they can also be taught and fostered. If fostering skills in innovation and the ability to effectively compete in the world economy are important, then curiosity and imagination might be appropriate skills for debate any future modification of Criterion 3 learning outcomes. Furthermore, greater emphasis on creativity and imagination may increase the appeal of engineering for women and minorities.

Persisten $(t / c e)$ is also a characteristic that can be fostered and is one of the indicators of high self-efficacy. Individuals who persist in the face of failure, or when attempting a difficult and complex task, do so because of their belief in their ability to ultimately be successful ${ }^{1}$. A focus on increasing persistence and thus self-efficacy would help retain both women and men in engineering majors.

The themes of Experience, Hands-on, Take Apart, Mechanical, Tinkerer, and Visual/Spatial are also closely related to retention of students in engineering, especially women students. As the research cited earlier indicates, women have much less prior experience with engineering activities, especially those that involve mechanical devices, taking things apart and putting them back together or using their hands to build artifacts. Furthermore, research has shown that visualspatial ability is highly correlated to success in science. Even though women often have poorer spatial ability than men, it has been known since the 1980s that this difference can be quickly eliminated through carefully constructed interventions 9 .

Engineering programs that successfully address these gender-related issues identified by the engineers and engineering students in this research will have opportunities to bring more women into engineering, retain them, and help them graduate and foster their future graduate school and career success.

\section{Partially Corresponding Themes}

These themes were Creative, How Things Work, and Technical. Like Curious/Inquisitive and imagination, the creative theme contained some affective and motivational statements that aren't present among the Criterion 3 outcomes and reflected a more artistic interpretation of creating. Other statements were more reflective of Outcome (c), an ability to design and conduct experiments, as well as to analyze and interpret data, which reflects a more practical or technical interpretation of being creative. Both interpretations would have value engineering curriculum since a combination of artistic and practical/technical approaches have the potential to appeal to 
a broader and more diverse body of students who can bring innovation and fresh approaches to engineering.

Some statements associated with the theme How Things Work and Technical corresponded with Outcome (e) an ability to identify, formulate, and solve engineering problems. However, others reflect skills that males acquire through pre-engineering activities and experiences that women often do not experience in their daily lives or their academic pursuits. Like the themes of Experience, Hands-on, Take Apart, Mechanical, Tinkerer, and Visual/Spatial, some aspects of the themes of How Things Work and Technical identified by the engineers and engineering students in this study are closely related to the recruitment, retention, and graduation of women in engineering majors. Curricula that help women develop "technical know how (what stuff goes where)" and develop an "intuitive sense of how things work" would build self-efficacy in engineering design, activities, and problem solving and could help reduce the numbers of both men and women from leaving engineering majors.

\section{Strongly Corresponding Themes}

The themes that corresponded strongly with the ABET criterion 3 a-k learning outcomes were Knowledge/Background, Math, Problem Solving, Concepts, Think/Reason, Analytical, Communicate, Theory, Tools, Design, and Logic. Thus, approximately half of the themes related to tinkering and technical skills that engineers valued and considered important corresponded with Criterion 3 learning outcomes. Knowledge/Background corresponded with Outcome (h) the broad education necessary to understand the impact of engineering solutions in a societal context, and Outcome (j), a knowledge of contemporary issues. Math and Theory corresponded with Outcome (a) an ability to apply mathematics, science and engineering appropriate to the discipline. Problem Solving corresponded with Outcome (a) an ability to apply mathematics, science and engineering appropriate to the discipline, and Outcome (e) an ability to identify, formulate and solve engineering problems. Concepts, Think/Reason, and Logic corresponded with Outcome (e) an ability to identify, formulate and solve engineering problems, Analytical corresponded with Outcome (b) an ability to design and conduct experiments, analyze and interpret data, and Outcome (c) an ability to identify, formulate and solve engineering problems. Communicate corresponded with Outcome (g) an ability to communicate effectively. Tools corresponded with Outcome (k) an ability to use the techniques, skills and modern engineering tools necessary for engineering practice. Design corresponded with Outcome (c) an ability to design a system, component, or process to meet desired needs. Correspondence with these outcomes is not surprising since they are necessary skills for engineers. However, it could be also be argued that they are alone not sufficient for fostering interest and diversity in engineering.

\section{Non-corresponding Outcomes}

Some of the Criterion 3 outcomes did not correspond to the characteristics related to technical and tinkering skills. These included Outcomes (d), an ability to function on multidisciplinary teams; (f), an understanding of professional and ethical responsibility and; (i) a recognition of the need for, and an ability to, engage in lifelong learning did not appear on anyone's list of skills. The absence of Outcomes (d), (f), and (i) indicates that the "soft" outcomes may be on the 
periphery or may not be incorporated at all into the activities, thinking processes, or decision making processes of students, faculty and practicing engineers. As such, it might be useful to pose a question as to whether or not these outcomes may be more implicit than explicit in engineering curricula and do they need more articulation and emphasis in curricula. This includes the idea that there may be a need to make students explicitly aware that they are important aspects of their engineering education. The possibility also exists that the characteristics of tinkering and technical skills are words that may not be closely enough related to the concepts embodied in the Outcomes (d), (f), and (i).

\section{Implications and Questions for ABET Criteria and Engineering Curricula}

How should differences be viewed about characteristics of individuals with good technical and tinkering skills between students, faculty and practicing engineers? One way is to view them as the differences between a novice and expert practitioners. Newly graduated engineers are novices who, as they gain experience, will acquire both new skills and hone existing skills. Undergraduate engineering programs should not be expected to produce experts with a complete repertoire of skills, but should be expected to produce competent novices.

There is also another way to view these differences. That is that, the differences between the characteristics that engineers relate to tinkering and technical activities and the ABET Criterion 3 a-k learning outcomes, indicate that the emphasis and direction of ABET criteria and engineering curricula would benefit from some healthy debate. Questions could be posed about whether greater emphasis needs to be placed on the "softer" outcomes and whether ABET criteria should be broadened to include outcomes that build self-efficacy and foster curiosity, imagination and creativity.

\section{Implications for the Development of a Self-efficacy Instrument}

The results also indicate that, starting with the practitioners of a field, as recommended by Bandura $^{1}$, is not sufficient for building an instrument for technical and tinkering self-efficacy that can predict achievement and identify those who might be at risk for leaving engineering majors. The factors that are used to structure and evaluate engineering curricula must also be taken into consideration. The strong and partial correspondence of important tinkering and technical characteristics with Criterion 3 a-k learning outcomes provide important input for the selection and creation of items for a prototype self-efficacy instrument. The results will also provide a foundation for establishing the validity of the instrument. The next step is to build the instrument and administer it so that a factor analysis and reliability study can be conducted. The ultimate impact of this research and the creation of an instrument would be able to provide researchers with a tool capable of assessing new types of interventions to improve technical and tinkering self-efficacy to see which are most effective in positively impacting retention and achievement of engineering majors, and especially so for women and minorities. 


\section{References}

1. Bandura, A. (1977). Self-efficacy: The exercise of Control. New York: W.H. Freeman and Company.

2. Crismond, D. (2001). Learning and using science ideas when doing investigate-and- redesign tasks: A study of naive, novice, and expert designers doing constrained and scaffolded design work. Journal of Research in Science Teaching, 38, 791-820.

3. Margolis, J. \& Fisher, A. (2002). Unlocking the Clubhouse: Women in Computing. Cambridge: MA: The MIT Press.

4. Baumert, J., Evans, R. \& Geiser, H. (1998). Technical problem solving among 10-year-old students as related to science achievement, out of school experiences, domain-specific control beliefs, and attribution patterns. Journal of Research in Science Teaching, 35, 987-1013.

5. Forgasz, H., Leder, G. \& Kloosterman, P. (2004). New Perspectives on the gender stereotyping of mathematics. Mathematical Thinking and learning, 6(4), 389-420.

6. Grandee, J. (1997). Gender differences in the experiences, achievements, and expectations of science and engineering majors. Journal of Women and Minorities in Science and Engineering, 3, 119-143.

7. Wood, S. (2002). Perspectives on best practices for learning gender-inclusive science: Influences of extracurricular science for gifted girls and electrical engineering women. Journal of Women and Minorities in Science and Engineering, 8, 25-40.

8. Fuller, H. (1997). A study of confidence by gender. In Proceeding of the American Society for Engineering Education Annual Conference, Milwaukee, WI.

9. Ben-Chaim, David, G. Lappan \& R. Houang (1988). The effect of instruction on spatial visualization skills of middle school boys and girls. American Educational Research Journal, 25, 51-71. 